\title{
Diseño de instrumento para la medición de factores de éxito en franquicias de alimentos y bebidas: caso de estudio *
}

\author{
Designing an Instrument to Measure the Success Factors of Food and Beverage \\ Franchises: Case Study
}

\author{
Cristopher Sevilla-Bermúdez \\ Estudiante de Administración de Empresas, Instituto Tecnológico de Costa Rica, \\ San Carlos-Costa Rica, cristosb1023@gmail.com \\ Rony Mauricio Rodríguez-Barquero \\ Doctor en Dirección de Empresas, Instituto Tecnológico de Costa Rica, \\ San Carlos-Costa Rica, rrodriguezb@tec.ac.cr
}

Cómo citar / How to cite

Sevilla-Bermúdez, C.; Rodríguez-Barquero, R. M. (2021). Diseño de instrumento para la medición de factores de éxito en franquicias de alimentos y bebidas: caso de estudio. Revista CEA, v. 7, n. 14, e1677. https://doi.org/10.22430/24223182.1677

Recibido: 9 de octubre de 2020

Aceptado: 22 de febrero de 2021

\begin{abstract}
Resumen
La franquicia es un modelo de negocio que a lo largo de los años ha ganado importancia, convirtiéndose en una opción para la promoción de inversión. Sin embargo, falta información sobre este modelo en gestión que contribuya a la obtención de mejores resultados, por lo cual es necesaria la construcción de conocimiento exponencial que permita robustecer este modelo. El objetivo de este artículo fue diseñar un instrumento para medir factores de éxito en franquicias de alimentos y bebidas, tomando como caso de estudio franquicias de Monterrey, México, que han logrado un buen posicionamiento en su mercado. El diseño metodológico que se planteó fue cualitativo, donde se hizo una amplia revisión de la literatura, en la cual, a través de entrevistas a expertos en franquicias, se encontraron coincidencias de opiniones en los factores presentados; además, se propusieron posibles factores de éxito no contemplados al momento de la entrevista, lo cual ayudó a plantear una lista de 14 factores de éxito utilizados como base para el diseño de un cuestionario para la
\end{abstract}

\footnotetext{
* Este artículo se deriva del proyecto titulado «El modelo de negocio de franquicias como estrategia de desarrollo de la micro, pequeña y mediana empresa: el caso latinoamericano» y ha sido financiado con recursos del Instituto Tecnológico de Costa Rica.
} 
investigación en este campo. Con el desarrollo del modelo propuesto se observó que cada factor está relacionado entre sí vinculando cada aspecto de manera orgánica en el envío y recibimiento de información para la identificación de las dimensiones que aportan en mayor medida a este modelo de negocio.

Palabras clave: franquicias, factores de éxito en franquicias, industria alimenticia, modelo de negocio.

Clasificación JEL: M13, M16.

\section{Highlights}

- La implementación de los factores de éxito fortalece el desarrollo de franquicias.

- La construcción de conocimiento en materia de franquicias es necesaria para impulsar el desarrollo que hasta ahora ha tenido este modelo.

- El uso del cuestionario y del modelo de franquicia propuesto, permite continuar con la construcción de información y conocimiento para este modelo de negocio.

\section{Abstract}

Franchising, a business model that has grown in importance over the years, has become an option to promote investments. However, more information about this management model is necessary for it to produce better results, and further knowledge should be generated to strengthen it. The objective of this study is to design an instrument to measure success factors in food and beverage franchises based on the case of franchises in Monterrey, Mexico, that have achieved a good position in their market. The methodology was qualitative, including a thorough literature review and interviews with experts at franchises, which revealed shared opinions regarding success factors. Additional possible success factors that were not included in the interviews were proposed in order to complete a list of 14 success factors that was employed to design a questionnaire to be used in future research in this field. The model proposed here shows that all the factors are related to each other, linked in an organic way in which information is sent and received, and presents the dimensions that most contribute to this business model.

Keywords: Franchises, success factors in franchises, food industry, business model.

JEL classification: M13, M16.

\section{Highlights}

- The implementation of success factors strengthens franchise development.

- Knowledge about franchises should be advanced in order to boost the development that this business model has had so far.

- The questionnaire and franchise model proposed here can be used to construct information and knowledge for this business model. 


\section{INTRODUCCIÓN}

El modelo de negocio de franquicia es una posible forma de inversión más segura para quien desee emprender en un negocio (Farooq et. al., 2020; Méndez, et al., 2014). El hecho de que éste ya tenga algunos años de trayectoria en el mercado, acerca a la cúspide del éxito a todo aquel que se aventure en este modelo (Calderón- Monge et al., 2017). Sin embargo, la consolidación de información en este ámbito ha sido poca, por lo cual es importante construir información para lograr una mayor solidificación del modelo a nivel mundial (Murray \& Smyth, 2011). Acorde a lo mencionado en las líneas anteriores, Díez de Castro y Rondán Cataluña (2005), citados por Guerrero, et al., (2014), indican lo siguiente:

... el ritmo del avance de las investigaciones de carácter científico ha sido lento, lo cual ha estado condicionado por diversas razones, entre ellas: el desconocimiento de la franquicia a nivel académico, la falta de datos fiables y la complejidad del tratamiento de la franquicia por la visión totalizadora de las diferentes áreas del conocimiento sobre la empresa que requiere (p. 46).

Por lo tanto, el aporte de un cuestionario con los factores de éxito puede ser una oportunidad para que más investigadores en el área decidan tomarlo de apoyo para la realización de nuevas investigaciones que abonen al conocimiento en materia de franquicias.

Con base en todo lo expuesto, surge una pregunta de investigación que es necesaria para crear el cuestionario que se tuvo como objetivo: ¿cuáles son los factores de éxito que ayudan a las franquicias de la industria alimentaria a aumentar su competitividad en el mercado? Este interrogante nace con la finalidad de contribuir a uno de los objetivos de una investigación de mayor magnitud que aún se encuentra en estudio. Este estudio, de igual forma, tiene un enfoque en las franquicias que recibe el nombre de «El modelo de negocio de franquicia como estrategia de desarrollo de las pymes: el caso latinoamericano». Tanto el objetivo de la investigación como el problema de este artículo están fuertemente ligados, ya que el artículo puede ser el sustento de ese objetivo.

A partir de ese problema, generado en forma de pregunta, se inicia el abordaje del artículo, comenzando por una revisión de la literatura para poder identificar las posibles variables que aporten al éxito de una franquicia. Para delimitar la lista de factores de éxito se busca el apoyo de expertos en el área, en este caso de la ciudad de Monterey, México, quienes definen desde su experiencia cuáles están involucrados directamente con el éxito de la franquicia. Posteriormente, con la opinión de tres expertos, se compara la lista de factores presentados y se define una lista final de factores para luego crear el cuestionario que será propuesto.

\section{MARCO TEÓRICO}

\section{Franquicias}

En varios países de América Latina las franquicias han sido un modelo de negocio importante para el crecimiento empresarial (Melo et al., 2018), además ha venido tomando fuerza conforme transcurre el tiempo. En una entrevista realizada por la Revista Summa (2018) a la Federación Iberoamericana 
de Franquicias (FIAF), menciona que el nicho de las franquicias representó para el año 2017 el 2.4\% del PIB Latinoamericano. Pero ¿qué se entiende aquí por franquicia? Según Silva Duarte (2003), «las franquicias son modalidades de negocios en donde, mediante acuerdo comercial y financiero, una empresa denominada franquiciador permite utilizar su formato de negocios a otra llamada franquiciatario o franquiciado mediante el pago de regalías» (p. 118). Por otra parte, también podría indicarse que:

Una franquicia es un sistema de distribución de productos y/o de servicios, según el cual una empresa que ha logrado un éxito comercial en un área específica de negocios, transmite a otro empresario independiente todos sus conocimientos específicos y experiencia sobre el negocio original, a cambio de un derecho inicial más un porcentaje de regalías mensuales, permitiéndole el uso de sus marcas comerciales y símbolos distintivos. (Della Groce, 2016, p. 3)

En la búsqueda de complementar las definiciones anteriores es posible apoyarse de la definición de Guerrero et al. (2014), quienes afirman que:

... cuando con la licencia de uso de una marca se transmitan conocimientos técnicos o se proporcione asistencia técnica, para que la persona a quien se le concede pueda producir o vender bienes o prestar servicios de manera uniforme y con los métodos operativos, comerciales y administrativos establecidos por el titular de la marca, tendientes a mantener la calidad, prestigio e imagen de los productos o servicios a los que ésta distingue. (p. 47)

Analizando las definiciones anteriores, el término franquicia es un modelo de negocio en el cual el dueño de un negocio (franquiciante) cede secreto industrial y todo aquello que esté involucrado en el desarrollo del negocio a otra persona (franquiciatario) mediante un acuerdo contractual a cambio de remuneraciones y condiciones acordadas por las partes. Dentro de estas condiciones y términos se incluye el tipo de franquicias que el franquiciatario puede desarrollar, ya que acorde a las necesidades del negocio y los objetivos del franquiciante puede estar sujeta a variaciones, es por esto por lo que pueden existir varios tipos.

Mediante la revisión de literatura se logra encontrar dos grandes tipos de franquicias; el primero se enfoca según el tipo de negocio, que se puede relacionar con el «qué», ¿qué se vende?, ¿̇un producto, una parte de este o toda la idea negocio?, el segundo, se relaciona según la estrategia de expansión, que se puede relacionar con el "cómo y las reglas de juego para el franquiciatario», es decir, la forma y la cantidad de sucursales en que el franquiciatario podrá llevar a cabo la franquicia. En la Tabla 1 se realiza un abordaje mayor a la tipología de franquicias que comúnmente se puede encontrar. 
Tabla 1. Tipo de franquicias encontrados en la revisión de literatura

Table 1. Types of franchises found in the literature review

\begin{tabular}{|c|c|c|c|}
\hline & \multirow[b]{2}{*}{ Tipo } & \multicolumn{2}{|c|}{ Literatura } \\
\hline & & $\begin{array}{c}\text { Solís Vargas y Ponce Gonzales } \\
(2017, \text { pp. 11-12). }\end{array}$ & Della Groce (2016, pp. 4-5). \\
\hline \multirow[b]{2}{*}{$\begin{array}{l}\text { Según el tipo } \\
\text { de negocio }\end{array}$} & $\begin{array}{l}\text { Franquicias de } \\
\text { producto }\end{array}$ & $\begin{array}{l}\text { «Mediante este tipo de expansión } \\
\text { el franquiciante controla los } \\
\text { productos distribuidos por el } \\
\text { franquiciado». }\end{array}$ & $\begin{array}{l}\text { «Se transmite la posibilidad de } \\
\text { vender en forma exclusiva } \\
\text { determinados productos, cuya } \\
\text { aceptación en el mercado ya } \\
\text { está probada». }\end{array}$ \\
\hline & Formato de negocio & $\begin{array}{l}\text { «Este es el tipo de formato más } \\
\text { común y completo; el franquiciado } \\
\text { distribuye el producto y servicio } \\
\text { bajo la marca de un franquiciante». }\end{array}$ & $\begin{array}{l}\text { «El franquiciante transmite al } \\
\text { franquiciado toda su know- } \\
\text { how sobre la prestación de un } \\
\text { determinado servicio al } \\
\text { cliente, como ser Lavanderías, } \\
\text { Lavado de automóviles, } \\
\text { Inmobiliarias, Asesoramiento } \\
\text { Contable, Jardinería, Limpieza } \\
\text { de oficinas, etcétera». }\end{array}$ \\
\hline \multirow{4}{*}{$\begin{array}{c}\text { Según la } \\
\text { estrategia de } \\
\text { expansión }\end{array}$} & Franquicia máster & $\begin{array}{l}\text { «Es el medio de exportar una } \\
\text { franquicia del país de origen a otro, } \\
\text { el encargado de las operaciones en } \\
\text { el país extranjero atiende al } \\
\text { nombre de franquiciado máster, } \\
\text { quien es el encargado de la gestión } \\
\text { de la marca en el nuevo país; así } \\
\text { como el manejo del local piloto, } \\
\text { selección de nuevos franquiciados } \\
\text { en el territorio, estimar la inversión } \\
\text { y manejo de la publicidad de la } \\
\text { franquicia». }\end{array}$ & $\begin{array}{l}\text { «Es el contrato según el cual la } \\
\text { empresa franquiciante otorga } \\
\text { con exclusividad al } \\
\text { franquiciado la posibilidad de } \\
\text { desarrollar la franquicia en } \\
\text { una región determinada } \\
\text { otorgándole a su vez la } \\
\text { posibilidad de subfranquiciar } \\
\text { el negocio entre los } \\
\text { interesados locales». }\end{array}$ \\
\hline & Franquicia múltiple & $\begin{array}{l}\text { «Este tipo de franquicia cede a un } \\
\text { franquiciado o inversionista la } \\
\text { posibilidad de abrir más de un } \\
\text { establecimiento dentro de un área } \\
\text { determinada. Este es el único que } \\
\text { puede administrar los locales». }\end{array}$ & $\begin{array}{l}\text { «Es el acuerdo entre } \\
\text { Franquiciante y Franquiciado, } \\
\text { según el cual el primero } \\
\text { otorga al segundo la } \\
\text { posibilidad de abrir hasta un } \\
\text { número determinado de } \\
\text { locales en un área designada». }\end{array}$ \\
\hline & Plurifranquicias & $\begin{array}{l}\text { «El franquiciado asume el uso de } \\
\text { puntos de venta para el uso de } \\
\text { distintas marcas. Estas cadenas de } \\
\text { franquicia tienden a ser no } \\
\text { competitivas entre ellas y } \\
\text { complementarias». }\end{array}$ & No define. \\
\hline & $\begin{array}{l}\text { Franquicias } \\
\text { individuales }\end{array}$ & $\begin{array}{l}\text { «El propietario de una franquicia } \\
\text { máster o franquiciante inicial } \\
\text { concede a un inversionista el } \\
\text { desarrollo de las operaciones y } \\
\text { manejo de un solo establecimiento }\end{array}$ & $\begin{array}{l}\text { «Es el típico convenio según el } \\
\text { cual un empresario } \\
\text { independiente adquiere una } \\
\text { franquicia para operarla en } \\
\text { una sola unidad». }\end{array}$ \\
\hline
\end{tabular}




\begin{tabular}{lll}
\hline & $\begin{array}{l}\text { dentro de un espacio } \\
\text { determinado». }\end{array}$ & \\
\cline { 2 - 4 } & «Expansión desarrollada en centros & "Son franquicias cuyas \\
Franquicias córner & un espacio en el cual se venden & instalarse en muy pocos \\
& productos o prestan los servicios & metros cuadrados dentro de \\
del franquiciante». & otro tipo de negocio». \\
\hline
\end{tabular}

Para llevar a cabo una franquicia y lograr su éxito, deben tenerse en cuenta varias consideraciones (Link \& Merkert, 2011). Existen factores identificados en la literatura relacionados con el éxito de una franquicia (Chong \& Stephenson, 2020), lo que implica igualmente variedad de formas de medición de este. Dado lo anterior, cada uno de los autores lo desarrollaron acorde al enfoque de sus investigaciones, por ejemplo, utilizaron variables como competitividad, ventas, el empleo que generan las franquicias, la capacidad que tienen para internacionalizarse, entre otras Por esta razón, en la Tabla 2 se mencionan a los autores que han propuesto factores de éxitos en sus investigaciones y la forma en que miden el éxito en las franquicias, como puede verse a continuación.

Tabla 2. Forma en que los investigadores miden el éxito

Table 2. Aspects different authors have used to measure success

\begin{tabular}{|c|c|c|c|}
\hline Literatura & Medición del éxito & Literatura & Medición del éxito \\
\hline $\begin{array}{c}\text { Guerrero et al., } \\
(2014)\end{array}$ & $\begin{array}{c}\text { Ventas, utilidades y } \\
\text { empleo }\end{array}$ & Lee et al., (2015b) & $\begin{array}{c}\text { Desempeño del } \\
\text { negocio }\end{array}$ \\
\hline $\begin{array}{c}\text { Flores-Ortiz et al., } \\
(2015)\end{array}$ & Competitividad & Melo et al., (2015) & Internacionalización \\
\hline $\begin{array}{c}\text { Fernández Monroy y } \\
\text { Martín Santana } \\
\text { (2005) }\end{array}$ & Relaciones comerciales & Badrinarayanan et al., (2016) & Resonancia de marca \\
\hline Ulloa Soto (2012) & No se mide & Lee et al., (2015a) & Beneficios utilitarios \\
\hline Wu (2015) & Desempeño & & \\
\hline
\end{tabular}

Tal y como se mencionó en las líneas anteriores, para poder medir el éxito en una franquicia los autores se apoyan en la contribución de varios factores. Estos factores son pequeñas acciones que aportan en conjunto al éxito de las franquicias. Lo anterior fue encontrado por medio de una revisión de literatura y, para ser tomados en cuenta, debían estar relacionados en el área de interés, en este caso, la industria de alimentos y bebidas; además, debía ser producto de un estudio cuantitativo y ya que son el fuerte de nuestro artículo, son presentados junto a sus respectivos autores en la Tabla 3. 
Tabla 3. Factores de éxitos de las franquicias encontrados en la revisión de literatura

Table 3. Success factors of franchises found in the literature review

\begin{tabular}{|c|c|c|c|}
\hline Factor & Literatura & Factor & Literatura \\
\hline Know-how & $\begin{array}{l}\text { (Guerrero et al., 2014, } \\
\text { p.51) }\end{array}$ & Rápido crecimiento & (Guerrero et al., 2014, p. 51) \\
\hline $\begin{array}{l}\text { La calidad de la } \\
\text { relación }\end{array}$ & $\begin{array}{l}\text { (Guerrero et al., 2014, } \\
\text { p.51) }\end{array}$ & La ubicación & (Guerrero et al., 2014, p. 51) \\
\hline Factor & Literatura & Factor & Literatura \\
\hline $\begin{array}{l}\text { La selección del } \\
\text { franquiciatario }\end{array}$ & $\begin{array}{l}\text { (Guerrero et al., 2014, } \\
\text { p. 51) }\end{array}$ & Clima organizacional & $\begin{array}{l}\text { (Hernández, } 2012 \text { citado por } \\
\text { Flores-Ortiz et al., 2015, p. 28) }\end{array}$ \\
\hline $\begin{array}{l}\text { La satisfacción del } \\
\text { franquiciatario }\end{array}$ & $\begin{array}{l}\text { (Guerrero et al., 2014, } \\
\text { p. 51) }\end{array}$ & Compromiso & $\begin{array}{l}\text { (Anderson y Weitz, } 1992 \text { citado } \\
\text { por Fernández Monroy y Martín } \\
\text { Santana, 2005, p. 81) }\end{array}$ \\
\hline $\begin{array}{l}\text { La responsabilidad } \\
\text { compartida }\end{array}$ & $\begin{array}{l}\text { (Guerrero et al., 2014, } \\
\text { p. 51). }\end{array}$ & Confianza & $\begin{array}{l}\text { (Das y Teng, } 1998 \text { citado por } \\
\text { Fernández Monroy y Martín } \\
\text { Santana, 2005, p. 79) } \\
\text { (Wu, 2015, p. 1583) } \\
\text { (Uzzi, } 1997 \text { citado por } \\
\text { Badrinarayanan et al., 2016, p. } \\
\text { 3946) }\end{array}$ \\
\hline La integración vertical & $\begin{array}{l}\text { (Guerrero et al., 2014, } \\
\text { p. 51) }\end{array}$ & $\begin{array}{l}\text { Reconocimiento de } \\
\text { marca } \\
\text { Reputación de la cadena } \\
\text { Reputación de marca }\end{array}$ & $\begin{array}{l}\text { (Ulloa Soto, 2012) } \\
\text { (Melo et al., 2015) (Wu, 2015, p. } \\
\text { 1582) }\end{array}$ \\
\hline La capacitación & $\begin{array}{l}\text { (Guerrero et al., 2014, } \\
\text { p. 51) }\end{array}$ & Tasa de inversión & (Melo et al., 2015) \\
\hline Visión empresarial & $\begin{array}{l}\text { (Guerrero et al., 2014, } \\
\text { p. 51) }\end{array}$ & Compartir Conocimiento & (Wu, 2015, p. 1583) \\
\hline $\begin{array}{l}\text { Comunicación con } \\
\text { cliente }\end{array}$ & $\begin{array}{l}\text { (Guerrero et al., 2014, } \\
\text { p. 51) }\end{array}$ & Manejo de conflicto & (Wu, 2015) \\
\hline $\begin{array}{l}\text { Concepto o idea } \\
\text { comercial }\end{array}$ & (Ulloa Soto, 2012) & $\begin{array}{l}\text { Estrategia de la } \\
\text { franquicia }\end{array}$ & (Wu, 2015, p. 1582) \\
\hline $\begin{array}{l}\text { Conocimiento del } \\
\text { empresario sobre } \\
\text { franquicias }\end{array}$ & (Ulloa Soto, 2012) & Factores de gestión & (Lee et al., 2015b) \\
\hline $\begin{array}{l}\text { Grado de madurez de } \\
\text { la pyme }\end{array}$ & (Ulloa Soto, 2012) & Orientación del Mercado & (Lee et al., 2015b, p. 29) \\
\hline $\begin{array}{l}\text { Grado de } \\
\text { profesionalización del } \\
\text { recurso humano }\end{array}$ & (Ulloa Soto, 2012) & Estrategia competitiva & (Lee et al., 2015b, p. 30) \\
\hline $\begin{array}{l}\text { Acceso a consultores } \\
\text { en franquicias }\end{array}$ & (Ulloa Soto, 2012) & Bonos financieros & $\begin{array}{l}\text { (Berry, } 1995 \text { citado en Lee et al., } \\
2015 a, \text { p. 831) }\end{array}$ \\
\hline $\begin{array}{l}\text { Capacidad de } \\
\text { Crecimiento }\end{array}$ & (Melo et al., 2015) & Lazos sociales & (Lee et al., 2015a, p. 831) \\
\hline $\begin{array}{l}\text { Capacidad de } \\
\text { monitoreo y control }\end{array}$ & (Melo et al., 2015) & Enlaces estructurales & (Lee et al., 2015a, p. 832) \\
\hline $\begin{array}{l}\text { Especificidad de } \\
\text { conocimiento }\end{array}$ & $\begin{array}{l}\text { (Badrinarayanan et al., } \\
\text { 2016, p. 3945) }\end{array}$ & Equidad comercial & $\begin{array}{l}\text { (Davis y Mentzer 2008, citado por } \\
\text { Badrinarayanan et al., 2016, p. } \\
3946 \text { ) }\end{array}$ \\
\hline Especificidad del active & $\begin{array}{l}\text { (Badrinarayanan et al., } \\
2016, \text { p. 3945) }\end{array}$ & & \\
\hline
\end{tabular}




\section{METODOLOGÍA}

Este artículo responde a una metodología de investigación cualitativa. Para ello se realizó una amplia revisión documental que sirvió para consultar y obtener información de utilidad de acuerdo con el avance temático (Hernández Sampieri et al., 2014) de los factores de éxito en las franquicias. Se revisaron fuentes tanto primarias como secundarias, se utilizaron artículos de revistas académicas con no más de cinco años de publicación y, como criterio de relevancia, se utilizó la cantidad de citaciones del artículo y que se presenta en la Tabla 4.

Tabla 4. Categorización de la revisión de literatura

Table 4. Categorization of the literature review

\begin{tabular}{lcll}
\hline \multicolumn{1}{c}{ Fuente } & Citas & Revista \\
\hline (Lee et al., 2015b) & 100 & International Journal of Hospitality Management \\
\hline (Wu, 2015) & 40 & Journal of Business Research \\
\hline (Lee et al., 2015a) & 32 & Journal of Business \& Industrial Marketing \\
\hline $\begin{array}{l}\text { (Fernández Monroy y Martín Santana, } \\
\text { 2005) }\end{array}$ & 26 & $\begin{array}{l}\text { Revista Europea de Dirección y Economía de la } \\
\text { empresa }\end{array}$ \\
\hline (Badrinarayanan et al., 2016) & 25 & Journal of Business Research \\
\hline (Melo et al., 2015) & 21 & Revista de Administração de Empresas \\
\hline (Flores-Ortiz et al., 2015) & 12 & Revista Internacional Administración y Finanzas \\
\hline (Ulloa Soto, 2012) & 4 & Economía y sociedad \\
\hline (Guerrero et al., 2014) & 2 & Revista Internacional Administración y Finanzas \\
\hline
\end{tabular}

El tema de franquicias es novedoso en investigación, prueba de ello es que no hay ninguna revista con índice H5 que aparezca en las listas de relevancia en español, y en inglés solamente aparece la revista Franchise Law Journal con un índice H5 de 6. Dada la situación anterior, para validar la información, fueron realizadas entrevistas a profundidad con expertos en franquicias, estos fueron contactados por medio de correo electrónico para verificar su disposición de colaborar en la investigación. Al momento de estar en conversación con ellos, se explica el objetivo y de qué forma colaborarían con la investigación; los factores fueron planteados y los expertos, desde su experiencia, los aprobaban o descartaban debido a sus papeles en la investigación. A continuación, en la Tabla 5 se muestra el perfil de los entrevistadores participantes, con el objetivo de demostrar sus experiencias en el área.

Monterrey tiene una economía sumamente fuerte en México que cuenta con una gran cantidad de empresas que han surgido desde pequeños puestos en las calles hasta convertirse en franquicias sólidas en el mercado, por tal motivo, esta ciudad fue un lugar clave para el desarrollo del artículo, especialmente para el acercamiento con los expertos en franquicias, además de que se logró combinar con la actividad de Expofranquicia llevada a cabo en dicho lugar, enriqueciendo los conocimientos adquiridos en el tema de franquicias. 
Tabla 5. Perfil de los expertos y sus empresas

Table 5. Profiles of the experts and their companies

\begin{tabular}{|c|c|c|c|}
\hline Nombre del experto & $\begin{array}{c}\text { Puesto en la } \\
\text { empresa }\end{array}$ & $\begin{array}{c}\text { Nombre de la } \\
\text { empresa }\end{array}$ & Otros detalles \\
\hline Michelle Kava & Representante & $\begin{array}{l}\text { Dirección a } \\
\text { Soluciones JJT, } \\
\text { Sc }\end{array}$ & $\begin{array}{l}\text { Avalados por la Asociación Mexicana de } \\
\text { Franquicias (AMF), además, con } 6 \text { años de } \\
\text { experiencia }\end{array}$ \\
\hline Ana Gabriela Zavala & Representante & $\begin{array}{l}\text { Franquicia tu } \\
\text { negocio }\end{array}$ & $\begin{array}{l}\text { Avalados por la Asociación Mexicana de } \\
\text { Franquicias, además, cuenta con más de } 20 \\
\text { años de experiencia y con más de } 121 \\
\text { franquicias desarrolladas }\end{array}$ \\
\hline Enrique Alcázar & Representante & $\begin{array}{l}\text { Alcázar \& } \\
\text { Compañía }\end{array}$ & $\begin{array}{l}\text { Avalados por la Asociación Mexicana de } \\
\text { Franquicias, además, cuenta con una } \\
\text { experiencia de } 25 \text { años, tiene un alcance de } 18 \\
\text { países y como más de } 700 \text { franquicias } \\
\text { desarrolladas }\end{array}$ \\
\hline
\end{tabular}

Para llegar a la selección final de 14 factores se siguió un proceso para depurar la lista inicial de los 35 factores iniciales propuestos. De primera instancia, se realiza una minuciosa revisión de la literatura con la finalidad de encontrar factores de éxito en las franquicias y ser agregados a la lista, de la cual se encontraron un total de 35 factores de éxito; sin embargo, antes se debía corroborar su relación con la industria de alimentos y bebidas, así como los artículos con enfoque cuantitativo. El filtrado inicial se elaboró desde la perspectiva personal, se analizó el factor y el enfoque que cada autor le daba a cada factor y este era comparado con el enfoque del artículo, si el factor era compatible con el enfoque del artículo se mantenía en la lista de factores, de los 35 factores iniciales, se obtuvo 24.

Desde este punto era de suma importancia considerar la experiencia de los expertos en este proceso. Como tercer paso para depurar la lista de los 24 factores restantes fueron presentados a los expertos en franquicias, donde se entrevistaron tres expertos quienes, desde su punto de vista, indicaban si era o no un factor de éxito en la franquicia. Para ser tomado en cuenta en la lista final se debía coincidir en al menos dos opiniones positivas de los expertos, donde los 24 factores que existían se redujeron a 15 factores en lista de este proceso. Para obtener la lista final de 14 factores de éxito se realizó el análisis de las respuestas positivas y comentarios que hicieron los expertos. A causa de esto, se consideró conveniente la fusión de dos factores provocando la eliminación de un factor. A manera de resumen, en la Figura 1 se muestra el proceso que se llevó acabo para la selección de los factores de éxito seleccionado.

Con la lista final de 14 factores de éxito es esencial que cada factor fuese definido con el objetivo de comprender cómo se abordan cada uno de ellos. Para esto fueron utilizadas definiciones de otros autores y, en algunos casos, se tomó como referentes a varios autores para dar una definición propia que se ajustara al enfoque del artículo, la cual se presenta a continuación en la Tabla 6. 


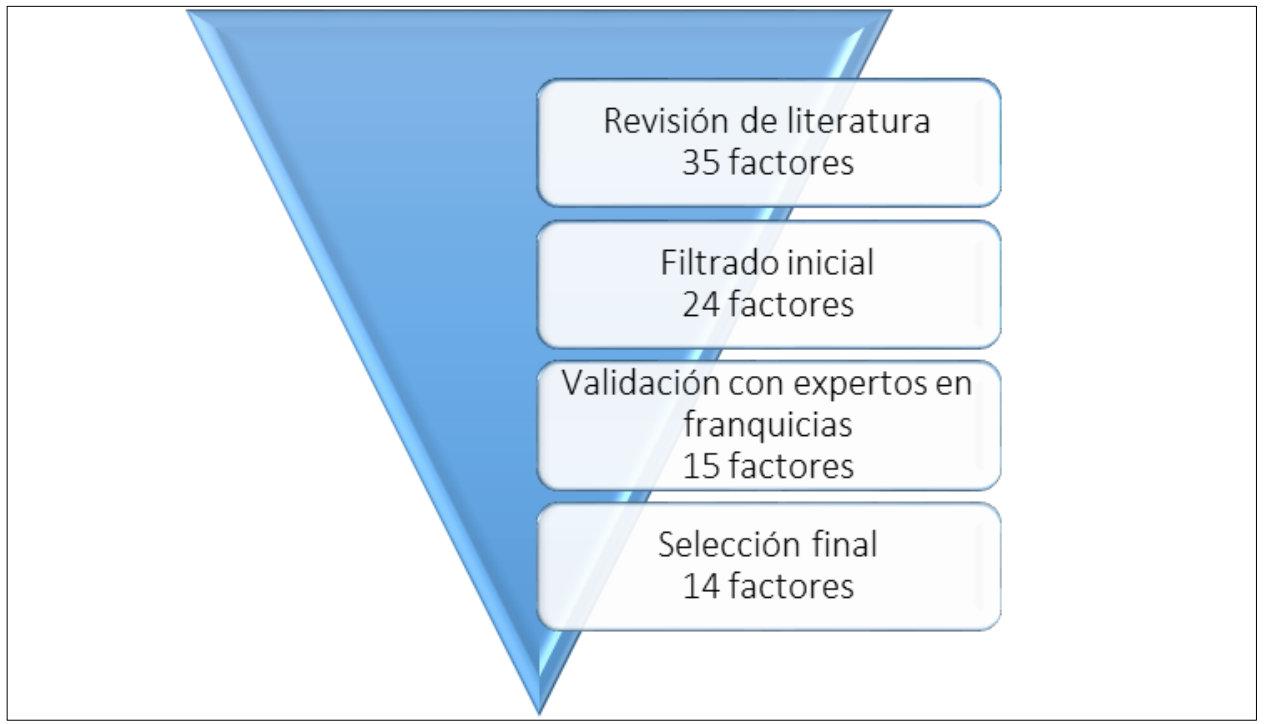

Figura 1. Efecto en selección de los factores de éxitos de las franquicias

Figure 1. Process to define success factors of franchises

Fuente: elaboración propia.

Nota: para la elección de los factores en la sección de «validación con expertos en franquicias» al menos dos expertos debían coincidir en su respuesta para ser tomado como factor de éxito.

Tabla 6. Lista de factores de éxito final

Table 6. Final list of success factors

\begin{tabular}{cll}
\hline Factor & \multicolumn{1}{c}{ Conceptuación } & \multicolumn{1}{c}{ Referente } \\
\hline Know-how & $\begin{array}{l}\text { Conjunto de información original y secreta que } \\
\text { desenvuelve los aspectos técnicos, comerciales y } \\
\text { económicos de un producto, servicio o empresa }\end{array}$ & $\begin{array}{l}\text { (Alfaro Rodríguez, } \\
\text { 2013, pp. 237-238) }\end{array}$ \\
\hline Actitud de una persona, organización, grupo, \\
Transparencia & $\begin{array}{l}\text { etcétera de dar a conocer, dar disponibilidad o } \\
\text { acceso a la información obtenida o creada por los } \\
\text { mismos }\end{array}$ & $\begin{array}{l}\text { (Uvalle en Arredondo et al., } \\
\text { 2014, p. 410) }\end{array}$ \\
\hline \multirow{2}{*}{$\begin{array}{c}\text { Manejo de } \\
\text { conflicto }\end{array}$} & $\begin{array}{l}\text { Forma y proceso en la que dos o más personas } \\
\text { solucionan el contraste de intereses u opiniones } \\
\text { presentados en un momento dado }\end{array}$ & $\begin{array}{l}\text { (Torrego en Gómez Funes, } \\
\text { (Vásquez et al., 2017) }\end{array}$ \\
\hline $\begin{array}{c}\text { Selección del } \\
\text { franquiciatario }\end{array}$ & $\begin{array}{l}\text { Proceso en el que el franquiciante decide cuál es la } \\
\text { persona idónea para que pueda hacer uso de su } \\
\text { secreto industrial }\end{array}$ & (Entrepreneur, 2010a; 2010b) \\
\hline \multirow{2}{*}{$\begin{array}{l}\text { Adaptación al } \\
\text { cambio }\end{array}$} & $\begin{array}{l}\text { Capacidad que tiene la organización para acoplarse, } \\
\text { adquirir o adaptarse a las nuevas tendencias de su } \\
\text { entorno y que este le demanda }\end{array}$ & $\begin{array}{l}\text { (Foronda Zapata, 2018, p. 13) } \\
\text { (Guzmán de la Rosa, } \\
\text { 2018, p. 7) } \\
\text { (Castañeda Gómez, 2011, p. 6) }\end{array}$ \\
\hline
\end{tabular}




\begin{tabular}{|c|c|c|}
\hline Capacitación & $\begin{array}{l}\text { Es un proceso planeado y estratégico que tiene por } \\
\text { objetivo actualizar o brindar nuevos conocimientos o } \\
\text { habilidades }\end{array}$ & $\begin{array}{l}\text { (García López, 2011, p. 4) } \\
\text { (Bermúdez Carrillo, 2015, p. 7) }\end{array}$ \\
\hline Visión empresarial & $\begin{array}{l}\text { Forma en la que una empresa ve su quehacer, sus } \\
\text { clientes y requerimientos para cumplirlos en un largo } \\
\text { plazo }\end{array}$ & $\begin{array}{l}\text { (González A. et al., } \\
\text { 2010, p. 45-46) }\end{array}$ \\
\hline $\begin{array}{l}\text { Estrategia de la } \\
\text { franquicia }\end{array}$ & $\begin{array}{l}\text { Son todas aquellas acciones diferenciales que realiza } \\
\text { la franquicia para obtener ventaja sobre sus } \\
\text { competidores y posicionarse en el mercado }\end{array}$ & $\begin{array}{l}\text { (Cynertia Consulting, } \\
\text { 2009, p. 3) } \\
\text { (Alaña Castillo et al., 2018, p. } \\
\text { 253) }\end{array}$ \\
\hline $\begin{array}{l}\text { Comunicación con } \\
\text { el cliente }\end{array}$ & $\begin{array}{l}\text { Son los medios y formas en que el cliente recibe y } \\
\text { emite información a la franquicia }\end{array}$ & Elaboración propia \\
\hline $\begin{array}{l}\text { Ubicación de los } \\
\text { puntos de venta }\end{array}$ & $\begin{array}{l}\text { Posición geográfica que deberá elegir la franquicia } \\
\text { acorde a sus necesidades y estrategias }\end{array}$ & Elaboración propia \\
\hline $\begin{array}{l}\text { Protección de } \\
\text { marca }\end{array}$ & $\begin{array}{l}\text { Es el registro de los signos de imagen que representa } \\
\text { a una empresa impulsado de actitudes accesibles } \\
\text { logrando que esté presente en la memoria del } \\
\text { consumidor }\end{array}$ & $\begin{array}{l}\text { (García Rodríguez, 1997). } \\
\text { (Organización Mundial de la } \\
\text { Propiedad Intelectual, 2006) }\end{array}$ \\
\hline $\begin{array}{l}\text { Mecanismo de } \\
\text { coordinación y } \\
\text { control }\end{array}$ & $\begin{array}{l}\text { Formas y medios que utiliza la franquicia para medir } \\
\text { resultados y asegurarse de que se cumpla con lo } \\
\text { acordado mediante el contrato }\end{array}$ & Elaboración propia \\
\hline Uso de tecnología & $\begin{array}{l}\text { Conjunto de tecnologías que mediante el uso de } \\
\text { aparatos electrónicos se gestiona y transforma la } \\
\text { información }\end{array}$ & $\begin{array}{l}\text { (Ayala Ñiquen y Gonzáles } \\
\text { Sánchez, 2015) } \\
\text { Sánchez Duarte (2008) }\end{array}$ \\
\hline Innovación & $\begin{array}{l}\text { Es la transformación o aplicación de nuevas ideas a } \\
\text { los productos, servicios, procesos, etcétera con el } \\
\text { objetivo de aumentar la competitividad y ofrecer algo } \\
\text { diferente }\end{array}$ & $\begin{array}{l}\text { (García González, 2012) } \\
\text { (Saenz et al., 2010) }\end{array}$ \\
\hline
\end{tabular}

Fuente: elaboración propia.

Se crea un instrumento en forma de un cuestionario para los 14 factores finales propuestos y que se encuentra más relacionado con el éxito de las franquicias. Cada factor tiene 5 ítems que lo aborda, donde se utiliza una escala Likert de 7 puntos ( 7 completamente de acuerdo, hasta 1 completamente en desacuerdo). Los ítems se dividen en dos grupos, los que fueron por elaboración propia y los que cuenta con un referente, ya que no se encontraron ítems acordes a cada factor. Los ítems con referentes fueron sometidos a los ajustes necesarios para que se alinearan al enfoque de la investigación, mientas que los demás tuvieron que ser propuestas propias por la falta de información como anteriormente se ha mencionado. Este listado de factores e ítems de medición se muestra en la Tabla 7. 
Tabla 7. Lista de factores de éxito final

Table 7. Success factors of franchises and items to measure them

\begin{tabular}{|c|c|c|}
\hline Factor & Indicador & Referentes \\
\hline Know-how & $\begin{array}{l}\text { 1- Es importante tener un know-how claro y concreto sobre } \\
\text { franquicias, tanto para el franquiciante como para el franquiciatario } \\
\text { 2- El know-how en franquicias proporciona ventaja competitiva para } \\
\text { el franquiciatario } \\
\text { 3- Antes de dar el salto para convertirse en franquicia, se debe contar } \\
\text { con el know-how } \\
\text { 4- Para una franquicia que no cuenta con un know-how claro es más } \\
\text { difícil competir en el mercado } \\
\text { 5- El know-how claro ayuda a que los franquiciantes se conecten } \\
\text { mejor a la idea del franquiciatario }\end{array}$ & Elaboración propia \\
\hline Transparencia & $\begin{array}{l}\text { 6- La transparencia en la gestión de la información fortalece la } \\
\text { relación entre franquiciante y franquiciatario } \\
\text { 7- Una franquicia es transparente cuando fomenta la participación y } \\
\text { actúa de manera ética con sus trabajadores y franquiciatarios } \\
\text { 8- La franquicia debe verificar periódicamente la veracidad de la } \\
\text { información que comunica a los diferentes interesados } \\
\text { 9- La falta de transparencia puede convertirse en una desventaja } \\
\text { para la franquicia } \\
\text { 10- La falta de transparencia genera desconfianza y rumores que } \\
\text { afectan negativamente a la franquicia }\end{array}$ & $\begin{array}{l}\text { Elaboración propia } \\
\quad \text { (Herranz de la } \\
\text { Casa, 2006, p. 343) } \\
\text { (Díaz et al., 2015, } \\
\quad \text { p. 7) } \\
\text { Elaboración propia } \\
\quad \text { (Herranz de la } \\
\text { Casa, 2006, p. 343) }\end{array}$ \\
\hline $\begin{array}{c}\text { Manejo de } \\
\text { conflicto }\end{array}$ & $\begin{array}{l}\text { 11- Es necesario seguir un procedimiento para el manejo de } \\
\text { conflictos en las franquicias } \\
\text { 12- Es necesaria la intervención de terceros para resolver conflictos } \\
\text { en las franquicias } \\
\text { 13- Debo solucionar los conflictos en mi franquicia lo antes posible } \\
\text { para evitar efectos negativos } \\
\text { 14- La constante frecuencia de conflictos es causante de una } \\
\text { reducción en la velocidad de expansión } \\
\text { 15- El adecuado manejo de conflictos abre las puertas a la mejora } \\
\text { continua }\end{array}$ & Elaboración propia \\
\hline $\begin{array}{l}\text { Selección del } \\
\text { franquiciatario }\end{array}$ & $\begin{array}{l}\text { 16- Es importante elegir bien al franquiciatario } \\
\text { 17- Se debe contar con un procedimiento para la selección del } \\
\text { franquiciatario } \\
\text { 18- Un mal franquiciatario puede dañar la imagen de la franquicia } \\
\text { 19- Los franquiciatarios correctos aportan al fortalecimiento y } \\
\text { competitividad de la franquicia } \\
\text { 20- Los franquiciatarios deben compartir la misma visión del } \\
\text { franquiciante, aunque este cumpla con lo establecido }\end{array}$ & Elaboración propia \\
\hline $\begin{array}{c}\text { Adaptación al } \\
\text { cambio }\end{array}$ & $\begin{array}{l}\text { 21- La adaptación al cambio ayuda a mantenerse en el mercado } \\
\text { 22- Se debe estar preparado para los posibles cambios del entorno } \\
\text { 23- Estar abiertos al cambio facilita la posibilidad de mejor y más } \\
\text { rápida adaptación a este } \\
\text { 24- Resistirse a los cambios genera que la franquicia pierda } \\
\text { competitividad en el mercado } \\
\text { 25- La adaptación al cambio debe de ir de la mano con el know-how }\end{array}$ & Elaboración propia \\
\hline Capacitación & $\begin{array}{l}\text { 26- Se debe realizar un diagnóstico de necesidades de capacitación } \\
\text { 27- Se cuenta con un plan de capacitación ya sea elaborado por la } \\
\text { misma o adquirido de un proveedor }\end{array}$ & Vecino (2012) \\
\hline
\end{tabular}




\begin{tabular}{|c|c|c|}
\hline & $\begin{array}{l}\text { 28- Se debe contar con un presupuesto para la capacitación de los } \\
\text { involucrados en la franquicia } \\
\text { 29- Se deben medir los resultados de la capacitación para verificar } \\
\text { que esta sea efectiva } \\
\text { 30- La capacitación ha sido portadora de mejora continua para la } \\
\text { franquicia }\end{array}$ & \\
\hline Visión empresarial & $\begin{array}{l}\text { 31- Fijar una visión ayuda al logro de objetivos de la franquicia } \\
\text { 32- Fijar una visión facilita la toma de decisiones en la franquicia } \\
\text { 33- La visión de la franquicia debe ser actualizada conforme a las } \\
\text { necesidades de la misma } \\
\text { 34- Es importante dar a conocer la visión a los franquiciantes y } \\
\text { potenciales franquiciantes } \\
\text { 35- Una franquicia sin visión complica el crecimiento o expansión de } \\
\text { la misma }\end{array}$ & Elaboración propia \\
\hline $\begin{array}{c}\text { Estrategia de la } \\
\text { franquicia }\end{array}$ & $\begin{array}{l}\text { 36- Tener una estrategia clara aumenta la competitividad de } \\
\text { franquicia } \\
\text { 37- Tener una estrategia clara ayuda a alcanzar la visión propuesta } \\
\text { 38- La falta de estrategias puede representar una debilidad para } \\
\text { competir en el mercado } \\
\text { 39- Las estrategias de la franquicia deben ser lo suficientemente } \\
\text { adaptable a los cambios que el mercado y la competencia lo exija } \\
\text { 40- La estrategia de franquicia debe ser compartida con los } \\
\text { franquiciantes para lograr un mayor éxito de las mismas }\end{array}$ & Elaboración propia \\
\hline $\begin{array}{c}\text { Comunicación con } \\
\text { el cliente }\end{array}$ & $\begin{array}{l}\text { 41- La franquicia debe tener comunicación con sus clientes para } \\
\text { conservarlos } \\
\text { 42- Se deben usar los mecanismos correctos para transmitir y recibir } \\
\text { información de los clientes } \\
\text { 43- El contenido de la información debe ser preciso y claro para que } \\
\text { el cliente logre comprenderlo } \\
\text { 44- La franquicia se debe interesar por conocer la percepción del } \\
\text { cliente } \\
\text { 45- La franquicia debe interesarse por conocer los gustos y } \\
\text { preferencias de los clientes }\end{array}$ & $\begin{array}{c}\text { Torres Camacho y } \\
\text { Jaramillo Gómez } \\
\text { (2015) }\end{array}$ \\
\hline $\begin{array}{l}\text { Ubicación de los } \\
\text { puntos de venta }\end{array}$ & $\begin{array}{l}\text { 46- Realizar un estudio de mercado antes de establecerse en un lugar } \\
\text { aumenta las posibilidades de éxito de la franquicia } \\
\text { 47- Una ubicación estratégica ayuda al posicionamiento de marca } \\
\text { 48- Una ubicación estratégica permite competir de mejor manera } \\
\text { 49- La ubicación de los puntos de venta deben aportar al } \\
\text { cumplimiento de estrategias y del know-how } \\
\text { 50- La ubicación de los puntos de ventas no pueden ser elegido sin } \\
\text { antes realizar el estudio y análisis correspondiente }\end{array}$ & Elaboración Propia \\
\hline $\begin{array}{l}\text { Protección de } \\
\text { marca }\end{array}$ & $\begin{array}{l}\text { 51- La protección de la marca, de los productos y servicios ayuda a } \\
\text { evitar que la competencia pueda tomar las ideas y perjudicar nuestra } \\
\text { franquicia } \\
\text { 52- La protección de marca es una ventaja que le ayuda a la } \\
\text { franquicia a competir en el mercado } \\
\text { 53- La protección de marca es un proceso que se debería de realizar } \\
\text { antes o en los inicios de la franquicia } \\
\text { 54- Antes de realizar una franquicia se debe considerar la protección } \\
\text { de marca de otras franquicias para que estas no perturben el proceso } \\
\text { de nuestra protección de marca } \\
\text { 55- La protección de marca nos evita falsificaciones o copias de la } \\
\text { marca de nuestra franquicia }\end{array}$ & Elaboración propia \\
\hline
\end{tabular}




\begin{tabular}{|c|c|c|}
\hline $\begin{array}{l}\text { Mecanismo de } \\
\text { coordinación y } \\
\text { control }\end{array}$ & $\begin{array}{l}\text { 56- El uso de manuales, procedimientos, controles internos y } \\
\text { sistemas de información y comunicación son parte esencial para la } \\
\text { coordinación y control de la franquicia } \\
\text { 57- Los mecanismos de coordinación y control contribuyen a una } \\
\text { gestión transparente de la franquicia } \\
\text { 58- Para optimizar el uso de recursos es necesario el uso de } \\
\text { mecanismos de coordinación y control } \\
\text { 59- Los mecanismos de coordinación y control, en la medida de lo } \\
\text { posible, deben ir de la mano con las Tecnologías de Información } \\
\text { 60- Se deben realizar auditorías o revisiones que corroboren la } \\
\text { veracidad de la información suministrada por los franquiciatarios }\end{array}$ & $\begin{array}{c}\text { Elaboración propia } \\
\text { (Aguilar Salvador, } \\
\text { 2017) }\end{array}$ \\
\hline Uso de Tecnologías & $\begin{array}{l}\text { 61- El uso de las tecnologías de información y comunicación facilita la } \\
\text { gestión de la información de la franquicia } \\
\text { 62- Las tecnologías con las que cuenta la franquicia deben ser } \\
\text { actualizadas cada cierta cantidad de tiempo o según lo demande la } \\
\text { franquicia y el mercado } \\
\text { 63- Con personal capacitado se maximiza el aprovechamiento de las } \\
\text { tecnologías de información y comunicación } \\
\text { 64- El uso de las tecnologías de información y comunicación agiliza y } \\
\text { simplifica procesos de la franquicia } \\
\text { 65- Con personal capacitado se maximiza el aprovechamiento de las } \\
\text { tecnologías de información y comunicación }\end{array}$ & $\begin{array}{c}\text { Elaboración propia } \\
\text { (Salazar Solano et } \\
\text { al., 2018) }\end{array}$ \\
\hline Innovación & $\begin{array}{l}\text { 66- La innovación ofrece ventaja competitiva a la franquicia } \\
\text { 67- La innovación ayuda al posicionamiento de la franquicia en el } \\
\text { mercado } \\
\text { 68- La innovación refresca el concepto de la franquicia } \\
\text { 69- A falta de innovación, genera que la franquicia se vaya } \\
\text { debilitando atreves del tiempo } \\
\text { 70- La innovación ayuda a que al franquicie mejore sus procesos y } \\
\text { servicios }\end{array}$ & Elaboración propia \\
\hline
\end{tabular}

Fuente: elaboración propia.

\section{RESULTADOS}

En la propuesta de este modelo se plantea una relación entre factores para lograr el éxito que se relaciona con el logro de objetivos. Entre cada factor hay un conector representado con una línea. Estos conectores en uno o en los dos extremos tiene un triángulo convirtiendo estas en flechas. El factor que recibe la flecha, solo recibe información del otro factor como, por ejemplo: la selección del franquiciatario recibe información del know-how, por tal motivo, la selección del franquiciatario debe ajustarse o crearse acorde a lo que se plantee en el know-how. Por otra parte, cuando existe flecha en ambos sentidos como entre el know-how y la estrategia competitiva, se transmite información en ambos sentidos; es decir, la información que se obtenga de la estrategia competitiva puede modificar el know-how y viceversa. Para obtener una mayor claridad del modelo propuesto, se presenta la Figura 2. 


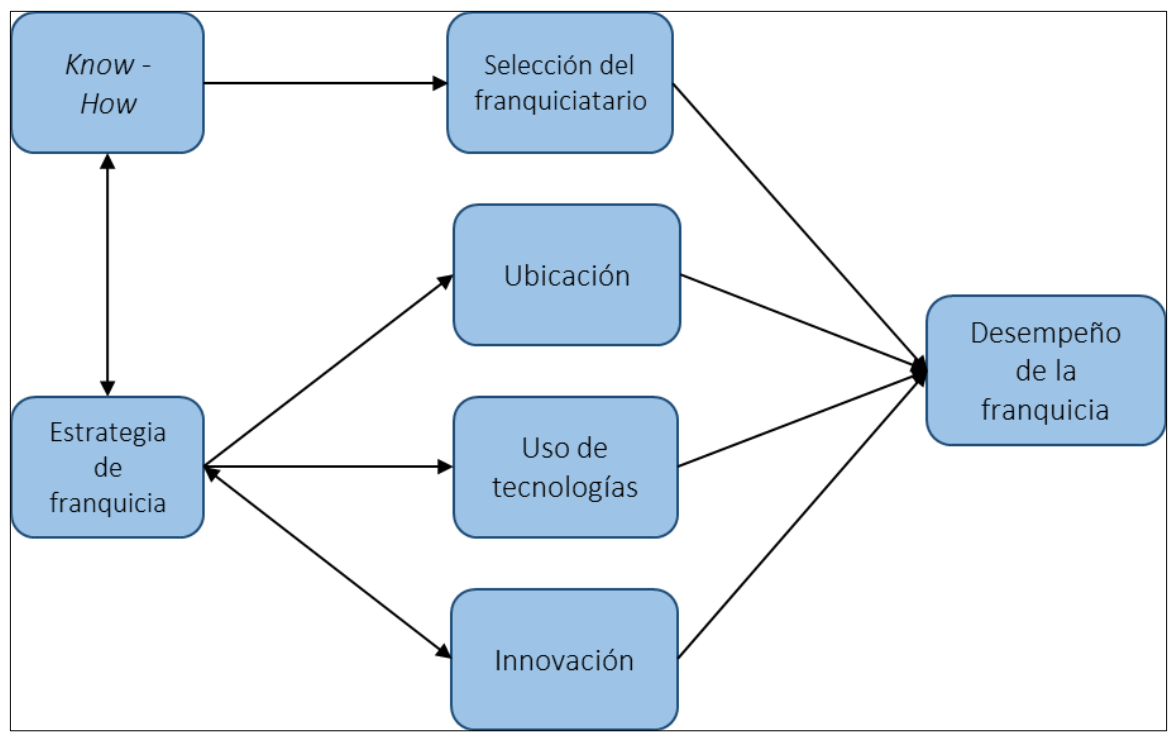

Figura 2. Modelo de factores de éxito propuestos para las franquicias

Figure 2. Model of success factors proposed for franchises

Fuente: elaboración propia.

Se plantea un instrumento que consta de 70 preguntas e integra los 14 factores de éxito formulados. Los ítems (ver Tabla 7) fueron formulados de forma afirmativa para que estos puedan ser analizados mediante herramientas estadísticas y se realice la validación respectiva. Dada la novedad del tema de franquicias en investigación, no se encontraron instrumentos validados cuyas publicaciones mencionaran los valores de fiabilidad de sus ítems; por tal motivo, se propone un instrumento propio que deberá ser validado empíricamente. Este se observa en la Tabla 8.

Tabla 8. Cuestionario propuesto

Table 8. Proposed questionnaire

\begin{tabular}{|c|c|c|}
\hline Factor & Preguntas & Respuestas \\
\hline \multirow{5}{*}{ Know-how } & $\begin{array}{l}\text { 1- Es importante tener un Know-how claro y concreto } \\
\text { sobre franquicias, tanto para el franquiciante como } \\
\text { para el franquiciatario }\end{array}$ & \multirow{5}{*}{$\begin{array}{l}\text { 1) Totalmente de acuerdo } \\
\text { 2) Muy de acuerdo } \\
\text { 3) De acuerdo } \\
\text { 4) Ni acuerdo, ni en desacuerdo } \\
\text { 5) En desacuerdo } \\
\text { 6) Muy en desacuerdo } \\
\text { 7) Totalmente en desacuerdo }\end{array}$} \\
\hline & $\begin{array}{l}\text { 2- El know-how en franquicias proporciona ventaja } \\
\text { competitiva para el franquiciatario }\end{array}$ & \\
\hline & $\begin{array}{l}\text { 3- Antes de dar el salto para convertirse en } \\
\text { franquicia, se debe contar con el know-how }\end{array}$ & \\
\hline & $\begin{array}{l}\text { 4- Para una franquicia que no cuenta con un know- } \\
\text { how claro es más difícil competir en el mercado }\end{array}$ & \\
\hline & $\begin{array}{l}\text { 5- El know-how claro ayuda a que los franquiciantes } \\
\text { se conecten mejor a la idea del franquiciatario }\end{array}$ & \\
\hline \multirow{2}{*}{ Transparencia } & $\begin{array}{l}\text { 6- La transparencia en la gestión de la información } \\
\text { fortalece la relación entre franquiciante y } \\
\text { franquiciatario }\end{array}$ & \multirow{2}{*}{$\begin{array}{l}\text { 1) Totalmente de acuerdo } \\
\text { 2) Muy de acuerdo } \\
\text { 3) De acuerdo } \\
\text { 4) Ni acuerdo, ni en desacuerdo } \\
\text { 5) En desacuerdo } \\
\text { 6) Muy en desacuerdo }\end{array}$} \\
\hline & $\begin{array}{l}\text { 7- Una franquicia es transparente cuando fomenta la } \\
\text { participación y actúa de manera ética con sus } \\
\text { trabajadores y franquiciatarios }\end{array}$ & \\
\hline
\end{tabular}




\begin{tabular}{|c|c|c|}
\hline & $\begin{array}{l}\text { 8- La franquicia debe verificar periódicamente la } \\
\text { veracidad de la información que comunica a los } \\
\text { diferentes interesados }\end{array}$ & 7) Totalmente en desacuerdo \\
\hline & $\begin{array}{l}\text { 9- La falta de la transparencia puede convertirse en } \\
\text { una desventaja para la franquicia }\end{array}$ & \\
\hline & $\begin{array}{l}\text { 10- La falta de transparencia genera desconfianza y } \\
\text { rumores que afectan negativamente a la franquicia }\end{array}$ & \\
\hline \multirow{5}{*}{$\begin{array}{l}\text { Manejo de } \\
\text { conflicto }\end{array}$} & $\begin{array}{l}\text { 11- Es necesario seguir un procedimiento para el } \\
\text { manejo de conflictos en las franquicias }\end{array}$ & \multirow{5}{*}{$\begin{array}{l}\text { 1) Totalmente de acuerdo } \\
\text { 2) Muy de acuerdo } \\
\text { 3) De acuerdo } \\
\text { 4) Ni acuerdo, ni en desacuerdo } \\
\text { 5) En desacuerdo } \\
\text { 6) Muy en desacuerdo } \\
\text { 7) Totalmente en desacuerdo }\end{array}$} \\
\hline & $\begin{array}{l}\text { 12- Es necesaria la intervención de terceros para } \\
\text { resolver conflictos en las franquicias }\end{array}$ & \\
\hline & $\begin{array}{l}\text { 13- Debo solucionar los conflictos en mi franquicia lo } \\
\text { antes posible para evitar efectos negativos }\end{array}$ & \\
\hline & $\begin{array}{l}\text { 14- La constante frecuencia de conflictos es causante } \\
\text { de una reducción en la velocidad de expansión }\end{array}$ & \\
\hline & $\begin{array}{l}\text { 15- El adecuado manejo de conflictos abre las } \\
\text { puertas a la mejora continua }\end{array}$ & \\
\hline \multirow{5}{*}{$\begin{array}{l}\text { Selección del } \\
\text { franquiciatario }\end{array}$} & 16- Es importante elegir bien al franquiciatario & \multirow{5}{*}{$\begin{array}{l}\text { 1) Totalmente de acuerdo } \\
\text { 2) Muy de acuerdo } \\
\text { 3) De acuerdo } \\
\text { 4) Ni acuerdo, ni en desacuerdo } \\
\text { 5) En desacuerdo } \\
\text { 6) Muy en desacuerdo } \\
\text { 7) Totalmente en desacuerdo }\end{array}$} \\
\hline & $\begin{array}{l}\text { 17- Se debe contar con un procedimiento para la } \\
\text { selección del franquiciatario }\end{array}$ & \\
\hline & $\begin{array}{l}\text { 18- Un mal franquiciatario puede dañar la imagen de } \\
\text { la franquicia }\end{array}$ & \\
\hline & $\begin{array}{l}\text { 19- Los franquiciatarios correctos aportan al } \\
\text { fortalecimiento y competitividad de la franquicia }\end{array}$ & \\
\hline & $\begin{array}{l}\text { 20- Los franquiciatarios deben compartir la misma } \\
\text { visión del franquiciante, aunque este cumpla con lo } \\
\text { establecido }\end{array}$ & \\
\hline \multirow{5}{*}{$\begin{array}{l}\text { Adaptación al } \\
\text { cambio }\end{array}$} & $\begin{array}{l}\text { 21- La adaptación al cambio ayuda a mantenerse en } \\
\text { el mercado }\end{array}$ & \multirow{5}{*}{$\begin{array}{l}\text { 1) Totalmente de acuerdo } \\
\text { 2) Muy de acuerdo } \\
\text { 3) De acuerdo } \\
\text { 4) Ni acuerdo, ni en desacuerdo } \\
\text { 5) En desacuerdo } \\
\text { 6) Muy en desacuerdo } \\
\text { 7) Totalmente en desacuerdo }\end{array}$} \\
\hline & $\begin{array}{l}\text { 22- Se debe estar preparado para los posibles } \\
\text { cambios del entorno }\end{array}$ & \\
\hline & $\begin{array}{l}\text { 23- Estar abiertos al cambio facilita la posibilidad de } \\
\text { mejor y más rápida adaptación a este }\end{array}$ & \\
\hline & $\begin{array}{l}\text { 24- Resistirse a los cambios genera que la franquicia } \\
\text { pierda competitividad en el mercado }\end{array}$ & \\
\hline & $\begin{array}{l}\text { 25- La adaptación al cambio debe de ir de la mano } \\
\text { con el know-how }\end{array}$ & \\
\hline \multirow{3}{*}{ Capacitación } & $\begin{array}{l}\text { 26- Se debe realizar un diagnóstico de necesidades } \\
\text { de capacitación }\end{array}$ & \multirow{3}{*}{$\begin{array}{l}\text { 1) Totalmente de acuerdo } \\
\text { 2) Muy de acuerdo } \\
\text { 3) De acuerdo } \\
\text { 4) Ni acuerdo, ni en desacuerdo } \\
\text { 5) En desacuerdo } \\
\text { 6) Muy en desacuerdo } \\
\text { 7) Totalmente en desacuerdo }\end{array}$} \\
\hline & $\begin{array}{l}\text { 27- Se cuenta con un plan de capacitación ya sea } \\
\text { elaborado por la misma o adquirido de un proveedor }\end{array}$ & \\
\hline & $\begin{array}{l}\text { 28- Se debe contar con un presupuesto para la } \\
\text { capacitación de los involucrados en la franquicia }\end{array}$ & \\
\hline
\end{tabular}




\begin{tabular}{|c|c|c|}
\hline & $\begin{array}{l}\text { 29- Se deben medir los resultados de la capacitación } \\
\text { para verificar que esta sea efectiva }\end{array}$ & \\
\hline & $\begin{array}{l}\text { 30- La capacitación ha sido portadora de mejora } \\
\text { continua para la franquicia }\end{array}$ & \\
\hline \multirow{5}{*}{$\begin{array}{l}\text { Visión } \\
\text { empresarial }\end{array}$} & $\begin{array}{l}\text { 31- Fijar una visión ayuda al logro de objetivos de la } \\
\text { franquicia }\end{array}$ & \multirow{5}{*}{$\begin{array}{l}\text { 1) Totalmente de acuerdo } \\
\text { 2) Muy de acuerdo } \\
\text { 3) De acuerdo } \\
\text { 4) Ni acuerdo, ni en desacuerdo } \\
\text { 5) En desacuerdo } \\
\text { 6) Muy en desacuerdo } \\
\text { 7) Totalmente en desacuerdo }\end{array}$} \\
\hline & $\begin{array}{l}\text { 32- Fijar una visión facilita la toma de decisiones en la } \\
\text { franquicia }\end{array}$ & \\
\hline & $\begin{array}{l}\text { 33- La visión de la franquicia debe ser actualizada } \\
\text { conforme a las necesidades de la misma }\end{array}$ & \\
\hline & $\begin{array}{l}\text { 34- Es importante dar a conocer la visión a los } \\
\text { franquiciantes y potenciales franquiciantes }\end{array}$ & \\
\hline & $\begin{array}{l}\text { 35- Una franquicia sin visión complica el crecimiento } \\
\text { o expansión de la misma }\end{array}$ & \\
\hline \multirow{5}{*}{$\begin{array}{l}\text { Estrategia de } \\
\text { franquicia }\end{array}$} & $\begin{array}{l}\text { 36- Tener una estrategia clara aumenta la } \\
\text { competitividad de franquicia }\end{array}$ & \multirow{5}{*}{$\begin{array}{l}\text { 1) Totalmente de acuerdo } \\
\text { 2) Muy de acuerdo } \\
\text { 3) De acuerdo } \\
\text { 4) Ni acuerdo, ni en desacuerdo } \\
\text { 5) En desacuerdo } \\
\text { 6) Muy en desacuerdo } \\
\text { 7) Totalmente en desacuerdo }\end{array}$} \\
\hline & $\begin{array}{l}\text { 37- Tener una estrategia clara ayuda a alcanzar la } \\
\text { visión propuesta }\end{array}$ & \\
\hline & $\begin{array}{l}\text { 38- La falta de estrategias puede representar una } \\
\text { debilidad para competir en el mercado }\end{array}$ & \\
\hline & $\begin{array}{l}\text { 39- Las estrategias de la franquicia deben ser lo } \\
\text { suficientemente adaptable a los cambios que el } \\
\text { mercado y la competencia lo exija }\end{array}$ & \\
\hline & $\begin{array}{l}\text { 40- La estrategia de franquicia debe ser compartida } \\
\text { con los franquiciantes para lograr un mayor éxito de } \\
\text { las mismas }\end{array}$ & \\
\hline \multirow{5}{*}{$\begin{array}{l}\text { Comunicación } \\
\text { con el cliente }\end{array}$} & $\begin{array}{l}\text { 41- La franquicia debe tener comunicación con sus } \\
\text { clientes para conservarlos }\end{array}$ & \multirow{5}{*}{$\begin{array}{l}\text { 1) Totalmente de acuerdo } \\
\text { 2) Muy de acuerdo } \\
\text { 3) De acuerdo } \\
\text { 4) Ni acuerdo, ni en desacuerdo } \\
\text { 5) En desacuerdo } \\
\text { 6) Muy en desacuerdo } \\
\text { 7) Totalmente en desacuerdo. }\end{array}$} \\
\hline & $\begin{array}{l}\text { 42- Se deben usar los mecanismos correctos para } \\
\text { transmitir y recibir información de los clientes }\end{array}$ & \\
\hline & $\begin{array}{l}\text { 43- El contenido de la información debe ser preciso y } \\
\text { claro para que el cliente logre comprenderlo }\end{array}$ & \\
\hline & $\begin{array}{l}\text { 44- La franquicia se debe interesar por conocer la } \\
\text { percepción del cliente }\end{array}$ & \\
\hline & $\begin{array}{l}\text { 45- La franquicia debe interesarse por conocer los } \\
\text { gustos y preferencias de los clientes }\end{array}$ & \\
\hline \multirow{3}{*}{$\begin{array}{l}\text { Ubicación de los } \\
\text { puntos de ventas }\end{array}$} & $\begin{array}{l}\text { 46- Realizar un estudio de mercado antes de } \\
\text { establecerse en un lugar aumenta las posibilidades de } \\
\text { éxito de la franquicia }\end{array}$ & \multirow{3}{*}{$\begin{array}{l}\text { 1) Totalmente de acuerdo } \\
\text { 2) Muy de acuerdo } \\
\text { 3) De acuerdo } \\
\text { 4) Ni acuerdo, ni en desacuerdo } \\
\text { 5) En desacuerdo } \\
\text { 6) Muy en desacuerdo } \\
\text { 7) Totalmente en desacuerdo }\end{array}$} \\
\hline & $\begin{array}{l}\text { 47- Una ubicación estratégica ayuda al } \\
\text { posicionamiento de marca }\end{array}$ & \\
\hline & $\begin{array}{l}\text { 48- Una ubicación estratégica permite competir de } \\
\text { mejor manera }\end{array}$ & \\
\hline
\end{tabular}




\begin{tabular}{|c|c|c|}
\hline & $\begin{array}{l}\text { 49- La ubicación de los puntos de venta deben } \\
\text { aportar al cumplimiento de estrategias y del know- } \\
\text { how } \\
\text { 50- La ubicación de los puntos de ventas no pueden } \\
\text { ser elegido sin antes realizar el estudio y análisis } \\
\text { correspondiente }\end{array}$ & \\
\hline \multirow{5}{*}{$\begin{array}{l}\text { Protección de } \\
\text { marca }\end{array}$} & $\begin{array}{l}\text { 51- La protección de la marca, de los productos y } \\
\text { servicios ayuda a evitar que la competencia pueda } \\
\text { tomar las ideas y perjudicar nuestra franquicia }\end{array}$ & \multirow{5}{*}{$\begin{array}{l}\text { 1) Totalmente de acuerdo } \\
\text { 2) Muy de acuerdo } \\
\text { 3) De acuerdo } \\
\text { 4) Ni acuerdo, ni en desacuerdo } \\
\text { 5) En desacuerdo } \\
\text { 6) Muy en desacuerdo } \\
\text { 7) Totalmente en desacuerdo }\end{array}$} \\
\hline & $\begin{array}{l}\text { 52- La protección de marca es una ventaja que le } \\
\text { ayuda a la franquicia a competir en el mercado }\end{array}$ & \\
\hline & $\begin{array}{l}\text { 53- La protección de marca es un proceso que se } \\
\text { debería de realizar antes o en los inicios de la } \\
\text { franquicia }\end{array}$ & \\
\hline & $\begin{array}{l}\text { 54- Antes de realizar una franquicia se debe } \\
\text { considerar la protección de marca de otras } \\
\text { franquicias para que estas no perturben el proceso } \\
\text { de nuestra protección de marca }\end{array}$ & \\
\hline & $\begin{array}{l}\text { 55- La protección de marca nos evita falsificaciones o } \\
\text { copias de la marca de nuestra franquicia }\end{array}$ & \\
\hline \multirow{5}{*}{$\begin{array}{l}\text { Mecanismos de } \\
\text { coordinación y } \\
\text { control }\end{array}$} & $\begin{array}{l}\text { 56- El uso de manuales, procedimientos, controles } \\
\text { internos y sistemas de información y comunicación } \\
\text { son parte esencial para la coordinación y control de la } \\
\text { franquicia }\end{array}$ & \multirow{5}{*}{$\begin{array}{l}\text { 1) Totalmente de acuerdo } \\
\text { 2) Muy de acuerdo } \\
\text { 3) De acuerdo } \\
\text { 4) Ni acuerdo, ni en desacuerdo } \\
\text { 5) En desacuerdo } \\
\text { 6) Muy en desacuerdo } \\
\text { 7) Totalmente en desacuerdo }\end{array}$} \\
\hline & $\begin{array}{l}\text { 57- Los mecanismos de coordinación y control } \\
\text { contribuyen a una gestión transparente de la } \\
\text { franquicia }\end{array}$ & \\
\hline & $\begin{array}{l}\text { 58- Para optimizar el uso de recursos es necesario el } \\
\text { uso de mecanismos de coordinación y control }\end{array}$ & \\
\hline & $\begin{array}{l}\text { 59- Los mecanismos de coordinación y control, en la } \\
\text { medida de lo posible, debe ir de la mano con las } \\
\text { Tecnologías de Información }\end{array}$ & \\
\hline & $\begin{array}{l}\text { 60- Se deben realizar auditorías o revisiones que } \\
\text { corroboren la veracidad de la información } \\
\text { suministrada por los franquiciatarios }\end{array}$ & \\
\hline \multirow{5}{*}{$\begin{array}{l}\text { Uso de } \\
\text { tecnologías }\end{array}$} & $\begin{array}{l}\text { 61- El uso de las tecnologías de información y } \\
\text { comunicación facilita la gestión de la información de } \\
\text { la franquicia }\end{array}$ & \multirow{5}{*}{$\begin{array}{l}\text { 1) Totalmente de acuerdo } \\
\text { 2) Muy de acuerdo } \\
\text { 3) De acuerdo } \\
\text { 4) Ni acuerdo, ni en desacuerdo } \\
\text { 5) En desacuerdo } \\
\text { 6) Muy en desacuerdo } \\
\text { 7) Totalmente en desacuerdo }\end{array}$} \\
\hline & $\begin{array}{l}\text { 62- Las tecnologías con las que cuenta la franquicia } \\
\text { deben ser actualizadas cada cierta cantidad de } \\
\text { tiempo o según lo demande la franquicia y el } \\
\text { mercado }\end{array}$ & \\
\hline & $\begin{array}{l}\text { 63- Con personal capacitado se maximiza el } \\
\text { aprovechamiento de las tecnologías de información y } \\
\text { comunicación }\end{array}$ & \\
\hline & $\begin{array}{l}\text { 64- El uso de las tecnologías de información y } \\
\text { comunicación agiliza y simplifica procesos de la } \\
\text { franquicia }\end{array}$ & \\
\hline & $\begin{array}{l}\text { 65- Se cuenta con un presupuesto para invertir en las } \\
\text { Tecnologías de Información }\end{array}$ & \\
\hline
\end{tabular}




\begin{tabular}{|c|c|c|}
\hline \multirow{5}{*}{ Innovación } & $\begin{array}{l}\text { 66- La innovación ofrece ventaja competitiva a la } \\
\text { franquicia }\end{array}$ & \multirow{5}{*}{$\begin{array}{l}\text { 1) Totalmente de acuerdo } \\
\text { 2) Muy de acuerdo } \\
\text { 3) De acuerdo } \\
\text { 4) Ni acuerdo, ni en desacuerdo } \\
\text { 5) En desacuerdo } \\
\text { 6) Muy en desacuerdo } \\
\text { 7) Totalmente en desacuerdo }\end{array}$} \\
\hline & $\begin{array}{l}\text { 67- La innovación ayuda al posicionamiento de la } \\
\text { franquicia en el mercado }\end{array}$ & \\
\hline & $\begin{array}{l}\text { 68- La innovación refresca el concepto de la } \\
\text { franquicia }\end{array}$ & \\
\hline & $\begin{array}{l}\text { 69- A falta de innovación, genera que la franquicia se } \\
\text { vaya debilitando atreves del tiempo }\end{array}$ & \\
\hline & $\begin{array}{l}\text { 70- La innovación ayuda a que al franquicie mejore } \\
\text { sus procesos y servicios }\end{array}$ & \\
\hline
\end{tabular}

\section{DISCUSIÓN}

A partir de los hallazgos encontrados junto al apoyo de los expertos en el área, se identificaron catorce factores de éxito para las franquicias de alimentos y bebidas: know-how, transparencia, manejo de conflicto, selección del franquiciatario, adaptación al cambio, capacitación, visión empresarial, estrategia de franquicia, comunicación con el cliente, ubicación de puntos de ventas, protección de marca, mecanismos de coordinación y control, uso de tecnologías e innovación. En este punto es importante indicar que para poder lograr una mejor compresión con esta parte del manuscrito es necesario mencionar lo siguiente: el referente más importante son los autores Guerrero et al., (2014) porque existe cierto grado de similitud en el enfoque de los artículos y es el que más ha repercutido en el proceso, ya que gran parte de los factores de éxito nacen con los autores citados; además, se mencionará el ejemplo concreto del gigante de McDonald's para evidenciar algunos de estos factores que no fueron tomados en cuentas por ellos.

Como bien se mencionó en líneas anteriores, debido a que existe un enfoque similar podemos iniciar por desarrollar aquellas variables en las que se fortalece un artículo con otro. El know-how es el factor básico de la franquicia, ya que comprende toda la información en detalle con el que se ha obtenido el éxito de nuestro negocio y que será transmitida a otra persona para que pueda lograr el éxito. Como prueba de esto, se menciona lo siguiente: «... el franquiciador cede a los franquiciados unas capacidades de gestión y el respaldo de un nombre de marca que permite que persona sin experiencia previa puedan dirigir un negocio con éxito» (Guerrero et al., 2014, p. 48), y esto se logra documentando y conociendo a la perfección cada dato que involucre a la franquicia y que además esto debe tener un acompañamiento con el factor de la selección del franquiciatario, ya que para Morrison (1997) en Guerrero et al. (2014), para que se pueden lograr buenos resultados tanto el franquiciante como el franquiciatario deberán cumplir un rol específico, esto refuerza la propuesta de relación entre el know-how y la selección del franquiciatario en el modelo de la Figura 2.

Junto a la selección del franquiciatario se abarcan dos factores más, pues desde el punto de vista de esta investigación se puede relacionar uno con otro, donde la capacitación y el manejo de conflictos son esos factores. Como bien se mencionó en el párrafo anterior, tanto el franquiciante como el franquiciatario deben cumplir, ya que, de lo contrario, puede causar conflictos que, como bien se sabe, con el pasar del tiempo genera una bola de nieve que va impactando en los resultados de la 
franquicia; por eso, como en todo negocio, es necesario contar con un proceso de manejo de conflictos que evite un impacto negativo en los resultados de la franquicia, ya sea producido por franquiciantes, franquiciatarios, colaboradores o demás involucrados en la franquicia; asimismo, es importante capacitarlos para que cada uno de ellos puedan ser potenciados en conocimientos teóricos y prácticos con la finalidad de aprovechar el talento humano que es sumamente importante en las empresas (Calderon-Monge et al., 2017).

«La planeación estratégica es un medio útil para conservar la ventaja comparativa así como para enfrentar la competencia» (Di Constanzo, 1997 en Guerrero et al., 2014, p. 49), la cual permite soluciones más rentables y competitivas (Ciro-Gallo, 2021), es por esto que es importante la estrategia y la visión que tenga el franquiciatario, pues será el camino que se trace para avanzar hacia el éxito para poder competir de forma sólida en el mercado; sin ellos, existen grandes posibilidades de que sea un negocio sin rumbo y con ideas sin llevar acabo, ya que los mercados son altamente competitivos y sin las estrategias adecuadas cualquier negocio puede ser tirado al precipicio por los competidores e incluso a los nuevos franquiciatarios se les dificultaría trabajar la franquicia porque no existe un norte o ideas claras que ejecutar y, por consiguiente, obtener buenos resultados.

Hasta este punto se ha logrado desarrollar similitudes con el principal referente, por tanto, es momento de enfatizar en aquellas diferencias y basarse en el ejemplo de McDonald's para argumentar la importancia de estos, haciendo énfasis en las siguientes líneas los factores de adaptación al cambio e innovación. Partiendo del hecho cultural de que en la India su inmensa población no consume carne proveniente de las vacas por ser considerados animales sagrados, en la Revista Semana (2012) menciona que "Mcdonalds ha decidido adaptarse al consumo y a las costumbres tradicionales y abrir establecimientos totalmente vegetarianos en India». Lo anterior lleva a plantear el siguiente interrogante: ¿cree usted que sin esta o alguna otra adaptación McDonald's hubiese tenido el mismo éxito o habría fracasado? Hasta las más grandes franquicias se han adaptado a los cambios para lograr asegurar su éxito. Si se observan los menús de esta franquicia de restaurantes de comida rápida en cada país, se encontrará en su carta la adaptación de platos correspondiente a ese país, lo cual es aprovechado para realizar innovaciones específicas de cada país.

Por otra parte, en una era altamente digitalizada como esta cabe preguntarse: sin el uso de medios tecnológicos, ¿una franquicia que no utilice este recurso podría tener el mismo impacto que otra que sí lo haga? Desde esta perspectiva, no, ya que los mercados actuales, ya sean clientes o franquiciatarios, realizan las primeras búsquedas por medio de redes sociales o sitios web en el que puedan obtener información de la franquicia o de cualquier negocio. Las nuevas formas publicitarias o de mercadeo se encuentra dirigidas a medios digitales; incluso, para obtener mejores resultados, optimización de recursos y disminución de tiempo de ejecución se busca apoyo a través de medios tecnológicos (Montoya Jaramillo et al., 2019), los cuales se pueden aprovechar para crear mecanismo de coordinación y control porque, como se dijo al inicio del apartado, se busca buenos resultados financieros. ¿Sin los controles requeridos se podría asegurar que esos resultados se están logrando o que sean ciertos? Es difícil saberlo, ya que, entre menos controles haya, existe menos posibilidad de comprobar la veracidad de la información que se obtenga.

Es por eso que este manuscrito propone un conjunto de factores, un cuestionario y un modelo, intentando abarcar todas las partes de una franquicia para que logre su éxito, además de la similitud 
de los factores del: know-how, selección del franquiciatario, capacitación, visión empresarial, estrategia de franquicia, comunicación con el cliente y la ubicación de puntos de ventas (Guerrero et al., 2014); asimismo se agregan los factores de: protección de marca, mecanismos de coordinación y control, uso de tecnologías, innovación, transparencia, manejo de conflicto y adaptación al cambio con el objetivo de fortalecer los ya existentes y complementarlos con otros bajo el apoyo de expertos en el área. El cuestionario será de ayuda para poder crear mayor conocimiento de este modelo de negocios y seguir creciendo apoyado de la teoría como hasta ahora se ha hecho.

\section{CONCLUSIONES}

Existe poca información en el área de franquicias. Por tal motivo, con este tipo de artículos se contribuye a la construcción del conocimiento de este, ya que es un modelo de negocio que ha ido ganando importancia. En la revisión de la literatura se identificaron 35 factores de éxito propuestos por diferentes autores. La forma en que cada autor mide el éxito es variable, por tanto, el éxito de una franquicia no puede ser medido de una sola forma, por lo que se deben considerar varios aspectos para poder determinar si una franquicia es exitosa o no.

La entrevista a expertos en franquicias ayudó a precisar la información, ya que brindan aspectos a tomar en cuenta que no fueron encontrados por medio de la revisión de la literatura, con la experiencia de campo con la que ellos cuentan aportaron con la identificación de esos aspectos y se verificó lo planteado. La propuesta final se compone de 14 de factores de éxito para las franquicias, conformados por la revisión de literatura y las propuestas de los expertos en franquicias. Se ajustaron con base a la opinión de los consultores y se construye el instrumento de medición para evaluarlos, conformado de 70 ítems planteados de forma afirmativa. Además, se propuso un modelo conformado de 6 factores de éxito considerados como esenciales, es decir, factores que deben estar presentes en la gestión de la franquicia.

Debido a que el instrumento es una propuesta, este debe llevarse a prueba para realizar su respectiva validación para brindar una mayor fiabilidad. Una vez validado el instrumento, se pueden llevar a cabo investigaciones cuantitativas, ya que se pretende que los factores de éxitos puedan estandarizarse en diferentes partes del continente americano, y, por último, contribuir a la construcción de conocimiento en la materia. Se puede considerar el desarrollo de nuevos instrumentos que ayuden a obtener nueva información sobre el ámbito de franquicias para reforzar el tema, asimismo, se puede considerar agregar nuevos ítems, o bien restructurar los ya existentes con el objetivo de incrementar la confiabilidad del cuestionario.

Como valor agregado es de suma importancia mencionar que, tanto los factores de éxito, como el cuestionario propuesto, aportan al conocimiento teórico y práctico en el ámbito de los negocios; así las cosas, los potenciales franquiciatarios, los franquiciatarios y los franquiciantes podrán dar un paso más cerca de obtener el éxito para sus ideas de franquicias. Es necesario recordar que aún el desarrollo de información en el área es poca, es por esto que con la información recopilada en este artículo se puede crear una base para la construcción de nueva información en franquicias desde otras perspectivas, con la finalidad de fortalecer esta materia y, con el cuestionario validado, se podrá abrir la posibilidad de descubrir detalles que amplíen el estudio y la visión de las franquicias. 


\section{CONFLICTOS DE INTERÉS}

Los autores declaran que no presentan conflictos de interés financiero, profesional o personal que pueda influir de forma inapropiada en los resultados obtenidos o las interpretaciones propuestas.

\section{CONTRIBUCIÓN DE AUTORES}

Para el desarrollo de este proyecto todos los autores han realizado una contribución significativa especificada a continuación:

Cristopher Sevilla-Bermúdez: recopilación de la información, realizar las entrevistas respectivas con los expertos en el área, elaboración del modelo y el cuestionario.

Rony Mauricio Rodríguez-Barquero: revisión de los avances, aporte de ideas, encargado del proyecto principal.

\section{REFERENCIAS}

Aguilar Salvador, J. J. (2017). Los mecanismos de control interno y su impacto en los resultados de gestión, de las empresas del rubro transporte interprovincial de pasajeros de TambograndePiura en el año 2016 [Trabajo de grado]. URL

Alaña Castillo, T. P.; Crespo García, M. K.; Gonzaga Añazco, M. (2018). ¿Cómo las estrategias empresariales permiten una ventaja competitiva en las micro, pequeñas y medianas empresas de la provincia de El Oro? Universidad y Sociedad, v. 10, n. 2, 251-256. URL

Alfaro Rodríguez, M. V. (2013). El know how y su aplicación práctica en el contrato de franquicias. Revista Judicial, n. 109, 233-273. URL

Arredondo Trapero, F. G.; De La Garza García, J.; Vázquez Parra, J. C. (2014). Transparencia en las organizaciones, una aproximación desde la perspectiva de los colaboradores. Estudios Gerenciales, v. 30, n. 133, 408-418. https://doi.org/10.1016/i.estger.2014.06.007

Ayala Ñiquen, E. E.; Gonzales Sánchez, S. R. (2015). Lección 2. Tecnologías de la información y la comunicación. En Ayala Ñiquen, E; Gonzales Sánchez, S (Ed.). Tecnologías de la información y la comunicación (27-41). URL

Badrinarayanan, V.; Suh, T.; Kim, K.-M. (2016). Brand resonance in franchising relationships: A Franchisee-based perspective. Journal of Business Research, v. 69, n. 10, 3943-3950. https://dx.doi.org/10.1016/j.jbusres.2016.06.005

Bermúdez Carrillo, L. (2015). Capacitación: Una Herramienta de fortalecimiento de las PYMES. InterSedes, v. 16, n. 33, 1-25. https://doi.org/10.15517/ISUCR.V16133.19022 
Calderón-Monge, E., Pastor-Sanz, I.; Huerta-Zavala, P. (2017). Economic sustainability in franchising: A model to predict franchisor success or failure. Sustainability, v. 9, no. 8, 1419. https://doi.org/10.3390/su9081419

Castañeda Gómez, R. (2011). El proceso de cambio en las organizaciones [Tesis de maestría]. URL

Chong, K. L.; Stephenson, M. L. (2020). Deciphering Food Hawkerpreneurship: Challenges and success factors in franchising street food businesses in Malaysia. Tourism and Hospitality Research, v. 20, n. 4, 493-509. https://doi.org/10.1177/1467358420926695

Ciro-Gallo, E. O. (2021). Evaluación de metodologías de planeación estratégica en pymes del sector confección: estudio de caso. Revista CEA, v. 7, n. 13, e1634. https://doi.org/10.22430/24223182.1634

Cynertia Consulting. (2009). Estrategia empresarial: Cómo formularla e implementarla con éxito. URL

Della Groce, C. (2016). Franquicias. Control de gestión en empresas franquiciadoras. URL

Díaz Díaz, M. G.; Chávez Macías, A. G.; Hernández Aldaco, I. G. (2015). Comunicación corporativa, visibilidad y transparencia: su impacto en las organizaciones de la sociedad civil en México. Revista Internacional Administración \& Finanzas, v. 8, n. 3, 1-13. URL

Entrepreneur. (2010a, 28 de junio). Cómo elegir a tu franquiciatario. URL

Entrepreneur. (2010b, 23 de marzo). Tips para seleccionar al mejor franquiciatario. URL

Farooq, Q.; Liu, X.; Ahmad, S.; Fu, P.; Awan, H. M. (2020). Comparative analysis of entrepreneurship and franchising: CSR and voluntarism perspective. Voluntas, v. 31, 1-6. https://doi.org/10.1007/s11266-019-00152-1

Fernández Monroy, M.; Martín Santana, J. (2005). La confianza y el compromiso como factores claves del éxito de las relaciones comerciales: una aplicación empírica en el sistema de franquicias. Revista Europea de Dirección y Economía de la empresa, v. 15, n. 1, 77-100. URL

Flores-Ortiz, M. V.; Vega-López, A.; Chávez-Moreno, E. A. (2015). El clima organizacional como factor de competitividad en las franquicias de comida rápida en Tijuana, B.C, México. Revista Internacional Administración y Finanzas, v. 8, n. 5, 25-44. URL

Foronda Zapata, F. J. (2018). La adaptabilidad en las organizaciones. Una revisión teórica del concepto y los elementos que la configuran como una capacidad organizacional [Trabajo de grado de especialización]. URL

García González, F. (2012). Conceptos sobre innovación. URL 
García López, J. M. (2011). El proceso de capacitación, sus etapas e implementación para mejorar el desempeño del recurso humano en las organizaciones. Revista Contribuciones a la Economía. $\underline{U R L}$

García Rodríguez, M. J. (1997). Las ventajas de disponer de una marca fuerte en los mercados actuales. Investigaciones Europeas de Dirección y Economía de Empresas, v. 3, n. 3, 93-107. $\underline{\mathrm{URL}}$

Gómez Funes, G. (2013). Conflicto en las organizaciones y mediación. URL

González A., J. M.; Manrique Salas, O.; González Bonilla, O. (2010). La visión gerencial como factor de competitividad. Revista Escuela De Administración De Negocios, n. 69, 42-59. https://doi.org/10.21158/01208160.n69.2010.516

Guerrero Banderas, M. E.; Armenteros Acosta, M.C.; Medina Elizondo, M. (2014). Desarrollo estratégico de las franquicias mexicanas: estudio empírico en la comarca Lagunera, México. Revista Internacional Administración y Finanzas, v. 7, n. 6, 45-61. URL

Guzmán de la Rosa, A. E. Y. (2018). Adaptabilidad y proceso de cambio organizacional [Trabajo de grado]. URL

Hernández Sampieri, D.; Fernández Collado, C.; Baptista Lucio, M. del P. (2014). Desarrollo de la perspectiva teórica: revisión de la literatura y construcción del marco teórico. En: Metodología de la Investigación (58-87). MacGraw-Hill.

Herranz de la Casa, J. M. (2006). La comunicación y la transparencia en las organizaciones no lucrativas [Tesis de doctorado]. $\underline{\text { URL }}$

Lee, Y.-K.; Kim, S.; Kim, M.-S.; Lee, J.-H.; Lim, K.-T. Yong-Ki, L.; Sally, K.; Min-Seong, K.; Jae-Han, L.; KiTaek, L. (2015a). Relational bonding strategies in the franchise industry: the moderating role of duration of the relationship. Journal of Business \& Industrial Marketing, v. 30, n. 7, 830841. https://doi.org/10.1108/ibim-10-2013-0237

Lee, Y.-K.; Kim, S.-H.; Seo, M.-K. Hight, S. K.Yong-Ki, L.; Soon-Ho, K.; Min-Kyo, S.; Kyle, H. (2015b). Market orientation and business performance: evidence from franchising industry. International Journal of Hospitality Management, v. 44, 28-37. https://dx.doi.org/10.1016/j.ijhm.2014.09.008

Link, H.; Merkert, R. (2011). Success factors and pitfalls of regional rail franchising in Germany. International Journal of Transport Economics / Rivista Internazionale Di Economia Dei Trasporti, v. 38, n. 2, 173-200. $\underline{\text { URL }}$

Melo, P. L. R.; Mendes Borini, F.; De Miranda Oliveira Jr, M.; Couto Parente, R. (2015). Internationalization of brazilian franchise chains: a comparative study. Revista de Administração de Empresas, v. 55, n. 3, 258-272. https://doi.org/10.1590/S0034-759020150303 
Melo, P. L. R.; Mendes Borini, F. M.; Ogasavara, M. H. (2018). Latin American franchise internationalization: The impact of institutional environment. Thunderbird International Business Review, v. 61, n. 2, 217-228. https://doi.org/10.1002/tie.21975

Méndez, M. T.; Galindo, M. A.; Sastre, M. A. (2014). Franchise, innovation and entrepreneurship. The Service industries journal, v. 34, n. 9-10, 843-855. https://doi.org/10.1080/02642069.2014.905926

Montoya Jaramillo, C. A.; Montoya Jaramillo, L. J.; Ibarra Obando, C. H. (2019). Conceptualización de la Tecnología Blockchain para la Implementación de Contratos Inteligentes en las Franquicias. Revista CIES Escolme, v. 10, n. 2, 33-50. URL

Murray, B.; Smyth, H. (2011). Franchising in the US remodelling market: growth opportunities and barriers faced by general contractors. Construction Management and Economics, v. 29, n. 6, 623-634. https://doi.org/10.1080/01446193.2011.566622

Organización Mundial de la Propiedad Intelectual. (2006). El secreto está en la marca. España: OMPI. $\underline{U R L}$

Revista Semana. (2012, 9 de junio). McDonald's ahora es vegetariano en India. URL

Revista Summa. (2018). Franquicias crecen en Latinoamérica. URL

Saenz Blanco, F; Bertieri Quintero, J. R.; Villamarín Marentes, J. M. (2010). Innovación: Conceptos básicos. https://doi.org/10.13140/RG.2.2.18032.1024

Salazar Solano, V.; Moreno Dena, J. M.; Rojas Rodríguez, I. S.; Islas Olavarrieta, L. A. (2018). Nivel de adopción de tecnologías de la información y la comunicación en empresas comercializadoras de mango en Nayarit - México. Estudios Gerenciales, v. 34, n. 148, 292-304. https://doi.org/10.18046/j.estger.2018.148.2639

Sánchez Duarte, E. (2008). Las tecnologías de información y comunicación (TIC) desde una perspectiva social. Revista electrónica educare, v. 12, 155-162. https://doi.org/10.15359/ree.12-Ext.13

Silva Duarte, J. E. (2003). FRANQUICIAS. Una alternativa para emprendedores. Escuela de Administración de Negocios, n. 47, 116-121. URL

Solís Vargas, N. A.; Ponce Gonzales, J. S. (2017). Criterios y factores que definen el proceso de una selección de un franquiciado: propuesta de una guía técnica (Trabajo de grado). $\underline{\text { URL }}$

Torres Camacho, M. C.; Jaramillo Gómez, D. C. (2015). El marketing relacional en el proceso de fidelización de clientes. Caso grandes constructoras de Manizales. Inquietud empresarial, v. 15, n. 1, 165-185. URL 
Ulloa Soto, J. D. (2012). Franquicias nacionales: factores de éxito y fracaso. Economía y sociedad, v. 17, n. 42, 9-31. URL

Vásquez, C.; Ron, D.; Barry, J.; Barry, S. (2017). Manejo de conflictos. URL

Vecino Pico, J. M. (2012). 20 preguntas sobre capacitación empresarial. URL

Wu, C. -W. (2015). Antecedents of franchise strategy and performance. Journal of Business Research, v. 68, n. 7, 1581-1588. https://doi.org/10.1016/i.jbusres.2015.01.055 